\title{
RESPOSTAS LACTACIDÊMICAS E TEMPO LIMITE EM ESFORCOS SUPERIORES AO LIMIAR ANAERÓBIO: EFEITOS DA MÚSICA PREFERIDA E INFORMAÇẨO ENGANOSA
}

\author{
Rafael Lucas Cetein*, Leonardo Henrique Dalcheco Messias, João Pedro da Cruz, Felipe Marroni Rasteiro, \\ Claudio Alexandre Gobatto, Fúlvia de Barros Manchado-Gobatto.
}

\section{Resumo}

O objetivo do estudo foi investigar os efeitos da música preferida e informação enganosa sobre respostas lactacidêmicas e tempo limite (Tlim) em exercícios contínuos, individualizados com base na intensidade de limiar anaeróbio (iLAn). Dezoito individuos ativos e saudáveis ( $21 \pm 0$ anos) foram submetidos a cinco sessões de testes em cicloergômetro. Primeiramente, foram submetidos a um protocolo incremental para determinação da iLAn. Nas quatro sessões subsequentes, pedalaram em intensidade $20 \%$ superior à iLAn, mas adotando diferentes aplicações: i) sem música e sem informação enganosa quanto à intensidade de esforço; ii) com música; iii) aplicação da informação enganosa; iv) com música e sob efeito da informação enganosa. Demonstramos que a utilização da música preferida, conhecendo ou não a intensidade correta de esforço, não alteraram os parâmetros fisiológicos e o tempo de exaustão. No entanto, considerando as respostas individuais, é necessário cautela para afirmar se, de fato, não há efeito ergogênico atuante quando estímulos dessa natureza são aplicados.

\section{Palavras-chave:}

Música, informação enganosa, ciclismo, limiar anaeróbio, lactato sanguíneo, exaustão.

\section{Introdução}

A utilização de implementos externos na tentativa de potencializar a performance vem ganhando destaque

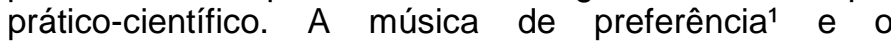
conhecimento prévio² (ou informação enganosa) sobre a intensidade de exercício vêm sendo investigados nesse sentido. No entanto, ainda não há evidências sobre o efeito de cada um ou ambos, em esforços exaustivos. Adicionalmente, para garantir similares condições entre avaliados, há a necessidade de individualizar o exercício com base em testes fisiológicos. Desse modo, o objetivo do estudo foi investigar o efeito da música de preferência e informação enganosa sobre respostas lactacidêmicas e tempo de exaustão (Tlim) durante exercício contínuo realizado em intensidade $20 \%$ superior ao limiar anaeróbio.

\section{Resultados e Discussão}

O teste incremental identificou a iLAn $(151,47 \pm 3,98 \mathrm{~W})$ e [Lac] iLAn $(4,90 \pm 0,29 \mathrm{mM})$ dos participantes. Não foram observadas diferenças sobre as variáveis analisadas (TT $p=0,563$; [Lac] $-p=0,823$ ) quando os indivíduos pedalaram nas quatro diferentes condições (figura 1). No entanto, $64,7 \%$ da amostra apresentou desempenho superior com a adoção conjunta da música e informação enganosa. Apenas a música ou informação enganosa elevaram o desempenho físico para $58,83 \%$ e $52,94 \%$ dos avaliados, respectivamente. Apesar de não existir diferença significante, analisando individualmente os casos, não excluímos a possibilidade dos efeitos estudados acionarem uma 'capacidade reserva' de energia, prolongando esforços exaustivos por meio da motivação musical ou ludibriamento sobre a intensidade imposta.
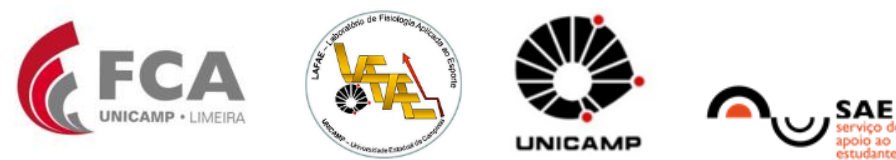

a)

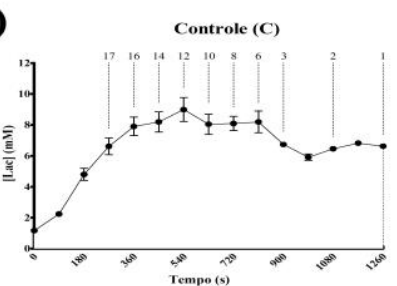

c)

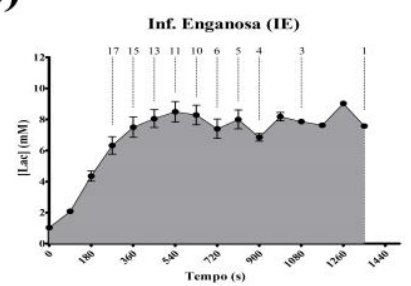

e)

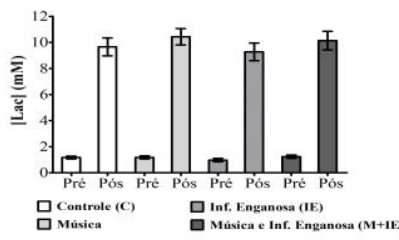

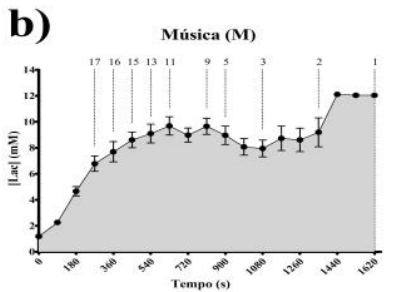

d)

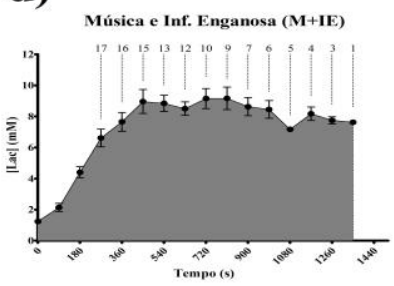

f)

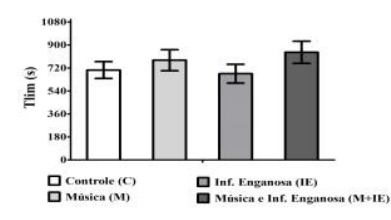

Figura 1. Cinética do lactato em esforços contínuos $20 \%$ acima do limia anaeróbio em cicloergômetro com $\mathrm{n}$ amostral apresentado nas curvas: sem intervenção (a), com música (b), com informação enganosa (c) com ambos (d), valores de lactato sanguíneo (e) e tempo de exaustão (f) em esforços supra-iLAn. Resultados expressos em média e erro padrão da média.

\section{Conclusões}

Concluímos que, embora análises individuais sugiram algum efeito da música de preferência e informação enganosa sobre o tempo limite de exercício em domínio severo, a análise de variância não revelou diferença entre as respostas lactacidêmicas e desempenho entre as quatro condições estudadas.

\section{Referências}

${ }^{1}$ Nakamura, P. M., Pereira, G., Papini, C. B., Nakamura, F. Y., \& Kokubun, E. Effects of preferred music and nonpreferred music on continuous cycling exercise performance. Perceptual and motor skills, 2010, 110(1), p. 257-264. 2 Taylor, D., \& Smith, M. F. Effects of deceptive running speed on physiology, perceptual responses, and performance during sprint-distance triathlon. Physiology \& behavior, 2014, 133 , p. 45-52. 